\title{
Verbenaceae SensU STRICTO Na Região de Xingó: Alagoas e Sergipe, Brasil
}

\author{
Juliana Silva dos Santos ${ }^{1,3}$, José Iranildo Miranda de Melo ${ }^{2}$, \\ Maria Carolina de Abreu ${ }^{1} \&$ Margareth Ferreira de Sales ${ }^{1}$
}

\begin{abstract}
RESUMO
(Verbenaceae sensu stricto na região de Xingó: Alagoas e Sergipe, Brasil) Este trabalho consiste no estudo taxonômico da família Verbenaceae s. s. em uma área de influência da Usina Hidrelétrica de Xingó, situada sob o domínio da região semi-árida, no nordeste brasileiro. A vegetação predominante é a Caatinga com diferentes fisionomias ainda pouco estudadas. Foram encontradas oito espécies distribuídas em três gêneros: Lantana camara L., Lantana canescens Kunth, Lippia alba (Mill.) N. E. Br., Lippia gracilis Schauer, Lippia microphylla Cham., Lippia pedunculosa Hayek, Stachytarpheta angustifolia (Mill.) Vahl e Stachytarpheta microphylla Walp. Nesta área, as espécies distribuem-se principalmente em ambientes secos, em solos areno-argilosos ou pedregosos, sendo as espécies do gênero Stachytarpheta Vahl encontradas em ambientes úmidos ou alagados. São fornecidas chaves de identificação para os gêneros e espécies, bem como ilustrações dos caracteres diagnósticos e comentários sobre distribuição geográfica dos táxons.
\end{abstract}

Palavras-chave: florística, Verbenaceae, Xingó, Caatinga.

\section{Abstract}

(Verbenaceae sensu stricto in the region of Xingó: Alagoas and Sergipe, Brazil) A taxonomic study for the family Verbenaceae s. s. was performed in the region of the influence area of the Xingó hydroelectric, situated under the domain of semi-arid region in northeastern Brazil. The predominant vegetation at the study area is Caatinga but phytosociological approaches for this area are lack. Eight species were found distributed in three genera: Lantana camara L., Lantana canescens Kunth, Lippia alba (Mill.) N. E. Br., Lippia gracilis Schauer, Lippia microphylla Cham., Lippia pedunculosa Hayek, Stachytarpheta angustifolia (Mill.) Vahl and Stachytarpheta microphylla Walp. In this area, the species are distributed mainly along dry environments in sandy-clayey or stony soils, and species of the genus Stachytarpheta Vahl found in flooded or wet environments. Identification keys for determining genera and species determinations are given, as well as illustrations with diagnostic characters and comments on geographical distribution of taxa.

Key-words: floristics, Verbenaceae, Xingó, Caatinga vegetation.

\section{INTRODUÇÃO}

Verbenaceae J.St.-Hil. compreende aproximadamente 36 gêneros e 1000 espécies de distribuição pantropical, com a maioria dos representantes nos neotrópicos. No Brasil ocorrem aproximadamente 17 gêneros e 250 espécies (Souza \& Lorenzi 2005). De acordo com dados recentes de filogenia, Verbenaceae sensu stricto está restrita aos gêneros com inflorescências racemosas e gineceu terminal, que delimitam a subfamília Verbenoideae (ElGazar \& Watson 1970; Raj 1983; Abu-Asab \& Cantino 1992; Cantino 1992a, b; Cantino et al. 1992; Wagstaff 1992; Steane et al. 2004;
Wagstaff et al. 1998; Judd 2009). Os demais gêneros com inflorescências cimosas e gineceu ginobásico foram segregados para a família Lamiaceae, ambas posicionadas no clado das Euasterídeas I, ordem Lamiales (APG 2003).

As espécies de Verbenaceae tem seu potencial econômico amplamente explorado, tanto como ornamentais (Lorenzi \& Souza 2001), quanto terapêuticas, neste último caso devido a presença de óleos essenciais. Muitos estudos atestam atividades analgésicas, antiespasmódicas, calmantes, sedativas, citostáticas, antimicrobianas, antitumorais, hepatoprotetoras, antiinflamatórias e laxativas

Artigo recebido em 08/2008. Aceito para publicação em 11/2009.

${ }^{1}$ Universidade Federal Rural de Pernambuco, Depto. Biologia, Programa de Pós-Graduação em Botânica, R. Dom Manoel de Medeiros s/n, Dois Irmãos, 52171-900, Recife, PE, Brasil.

${ }^{2}$ Universidade Estadual da Paraíba, Centro de Ciências Biológicas e da Saúde, Depto. Biologia, Av. das Baraúnas 351, Campus Universitário, Bodocongó, 58109-753, Campina Grande, PB, Brasil.

${ }^{3}$ Autor para correspondência: julyssantos@gmail.com 
de algumas de suas espécies (Stefanini et al. 2002). Além dessas, análises bioquímicas recentes atestam as propriedades de Lantana camara L. como repelente de mosquitos do gênero Aedes e de Stachytarpheta cayennensis (Rich) Vahl. como leishmanicida (Dua et al. 2003; Moreira et al. 2007).

Os principais tratamentos taxonômicos para a família foram realizados por Atkins (2005a), Bentham (1876), Briquet (1897), Junell (1934), Schauer (1847, 1851) e Troncoso (1974). A família é tratada também em floras de países da Ásia e Américas como China (ShouLiang \& Gilbert 1994), Argentina (Múlgura de Romero et al. 2003), Estados Unidos (Sanders 2001), Guianas (Jansen-Jacobs 1988), Panamá (Moldenke 1973) e Peru (Macbride 1960). Para o Brasil, destacam-se as revisões de Lantana, por Silva (1999); e Stachytarpheta, por Atkins (2005b); e as floras regionais: Bahia - de Mucugê e Pico das Almas (Harley \& Simmons 1986; Stannard 1995); Rio de Janeiro - Parati (Luizi-Ponzo 1997); Minas Gerais - Serra do Cipó (Salimena-Pires \& Giulietti 1998); e São Paulo - Ilha do Cardoso (Salimena 2000).

Devido à grande representatividade da família Verbenaceae no Brasil, este trabalho tem como objetivo fornecer dados sobre a distribuição dos táxons na região de Xingó; descrever e ilustrar caracteres morfológicos, vegetativos e reprodutivos, para a delimitação dos seus representantes, bem como fornecer chaves para identificação dos mesmos, visando contribuir para a expansão do conhecimento da flora da Caatinga, principalmente nos estados de Alagoas e Sergipe.

\section{Material e Métodos}

A região de Xingó está localizada no nordeste brasileiro $\left(09^{\circ} 30^{\prime}-10^{\circ} 00^{\prime} \mathrm{S}, 37^{\circ} 30^{\prime}-\right.$ $38^{\circ} 00^{\prime} \mathrm{W}$ ) na confluência dos estados de Alagoas, Sergipe, Bahia e Pernambuco, abrangendo 11 municípios sob o domínio da Caatinga, em uma altitude variando de 163 a $280 \mathrm{~m}$. Esta região se destaca por compreender a área de influência da Usina da Hidrelétrica de Xingó. A área estudada situa-se à jusante do rio São Francisco e abrange os municípios de Delmiro Gouveia,
Olho d' Água do Casado e Piranhas, em Alagoas, e de Canindé do São Francisco, situado em Sergipe. A vegetação dominante é do tipo Caatinga (Savana Estépica Arborizada - Veloso et al. 1992). O clima da região é característico do semi-árido, com precipitação anual de 500 mm (Cavalcanti et al. 2006) e temperatura média anual de $25^{\circ} \mathrm{C}$, sendo maior que $27^{\circ} \mathrm{C}$ nos meses mais quentes do ano (INPE 2001).

Os estudos foram baseados em coletas provenientes do Projeto "Flórula Fanerogâmica da Região de Xingó", realizadas entre os anos de 1999 e 2001, cujos materiais encontram-se depositados nos herbários PEUFR, UFP e no Herbário Xingó, o qual ainda não se encontra incluído no Index Herbariorum (Holmgren et al. 1990).

No intuito de analisar variações morfológicas intraespecíficas, adicionalmente, foram examinadas exsicatas, devidamente identificadas por especialistas, provenientes dos seguintes herbários: HST, IPA, PEUFR e UFP.

As descrições, chaves de gêneros e espécies foram fundamentadas nas variações observadas nos representantes coletados na região de Xingó, enquanto as descrições dos gêneros basearam-se na literatura. A padronização da terminologia das estruturas vegetativas e reprodutivas baseou-se em Harris \& Harris (2001), assim como as abreviações dos nomes dos autores foram fundamentadas em Brummit \& Powell (1992).

\section{Resultados e Discussão}

Verbenaceae J. St.-Hil., Expos. Fam. Nat. 1: 245. 1805. nom. cons.

Ervas, subarbustos, arbustos, árvores ou lianas. Folhas simples, decussadas, verticiladas, raramente alternas, sem estípulas. Tricomas uniou pluricelulares, simples, malpiguiáceos ou glandulares. Inflorescências terminais ou axilares, racemosas. Brácteas membranáceas ou foliáceas, verdes ou coloridas, por vezes carenadas, ovais a lanceoladas, densamente imbricadas ou laxamente dispostas. Flores andróginas ou unissexuadas por aborto, diclamídeas, zigomorfas, sésseis; cálice gamossépalo, membranáceo ou cartáceo, tubular ou cilíndrico, bordo denteado 
ou lobado; corola gamopétala, infundibuliforme ou hipocrateriforme, tubo reto ou encurvado, cilíndrico ou ventricoso, bilabiada, 4-5 lobada, prefloração imbricada. Estames 4, didínamos ou raramente 2 férteis e 2 estaminódios; anteras bitecas, tecas paralelas ou divergentes, deiscência rimosa, com ou sem apêndice do conectivo. Ovário súpero 2-carpelar, 2-locular, lóculos uniovulados, placentação parietal; estilete terminal, estigma capitado, às vezes oblíquo com papilas laterais. Fruto drupáceo ou esquizocárpico, com cálice persistente, drupa com mesocarpo carnoso e endocarpo ósseo ou cartilaginoso, esquizocarpo 2-4 mericárpico, unisseminado. Sementes sem endosperma, embrião reto.

\section{Chave para os gêneros de Verbenaceae na região de Xingó}

1. Inflorescências axilares; cálice até $2 \mathrm{~mm}$ compr.; estames 4, didínamos; estigma lateral com papilas

2. Inflorescências capituliformes, 1-2 por axila; brácteas oblongo-lanceoladas ou ovadas; cálice conspícuo 1. Lantana

2'. Inflorescências em glomérulos ou espigas, 1-4 por axila; brácteas orbiculares, ovais ou lanceoladas; cálice inconspícuo 2. Lippia

1'. Inflorescências terminais; cálice maior que 2 mm compr.; estames 2 e 2 estaminódios; estigma capitado ou orbicular sem papilas 3. Stachytarpheta

\section{Lantana L., Sp. Pl. 1: 626.1753.}

Ervas, subarbustos ou arbustos eretos. Ramos subquadrangulares a quadrangulares, escabro a hirto, tricomas simples. Folhas simples, decussadas, crenadas ou serreadas, frequentemente rugosas. Inflorescências pedunculadas, axilares, capituliformes ou espiciformes; brácteas ovais, oblongas ou lanceoladas. Flores andróginas; cálice tubular, reduzido, membranáceo, bordo denteado; corola vermelha, amarela, lilás, rosa ou alva, hipocrateriforme, tubo cilíndrico, geralmente encurvado, 4-5-lobada, lobos obtusos. Estames 4, didínamos, inclusos; anteras ovadas, tecas paralelas. Ovário 1-carpelar por aborto, estilete reduzido, estigma oblíquo. Fruto drupáceo, exocarpo carnoso. Sementes 2-pirenadas, pirenos uniloculados.

Segundo Troncoso (1974), o gênero engloba aproximadamente 250 espécies de distribuição tropical e subtropical, com poucos representantes ocorrendo na Ásia e África. Está representado no Brasil por 85 espécies (Silva 1999). Lantana é um gênero muito semelhante a Lippia, diferindo deste, principalmente, pela morfologia do fruto, que é drupáceo em Lantana e esquizocárpico em Lippia. Na região de Xingó, o gênero está representado por duas espécies.

\section{Chave para as espécies de Lantana ocorrentes na região de Xingó}

1. Pecíolo subquadrangular; brácteas oblongo-lanceoladas, ápice agudo; corola amarela a vermelha; ovário orbicular 1.1 Lantana camara

1'. Pecíolo cilíndrico; brácteas ovadas, ápice levemente caudado; corola alva de tubo róseo, ovário oblongo 1.2 Lantana canescens

1.1. Lantana camara L., Sp. Pl. 2: 267. 1753.

Fig. 1a-f

Subarbusto a arbusto 0,7-2 m. Ramos cinéreos ou castanhos, subcilíndricos a quadrangulares, escabros a pubescentes; internós 2-6,2 cm, presença de acúleos. Folhas cartáceas, discolores; pecíolo subquadrangular, ca. 6-9 mm compr., pubescente; limbo oval, $1,8-6,3 \times 1,6-4,5 \mathrm{~cm}$, face superior escabra a pubescente, face inferior escabra a híspida, base obtusa a truncada, margem serreada a crenada, ápice agudo-acuminado. Inflorescências capituliformes, axilares (1-2 por axila), pedúnculo 3-6,3 cm compr., escabro; brácteas 
cartáceas, oblongo-lanceoladas, 4,5-6×1 mm, pubescentes (na base) a estrigosas, tricomas glandulares, ápice agudo. Cálice 4-dentado, 1$1,5 \times 1 \mathrm{~mm}$, oval, pubescente, margem ciliada. Corola amarela a vermelha, levemente curva, 0,8-1 cm compr., lobos ca. $1,5 \times 1,5 \mathrm{~mm}$, fauce 1 mm diâm, tubo 6-8 mm compr., internamente pubescente. Estames inseridos na metade inferior (os menores) e na metade superior (os maiores) do tubo, anteras ovais. Ovário orbicular, ca. $0,5 \mathrm{~mm}$, glabro; estilete encurvado, ca. $1,3 \mathrm{~mm}$ compr., estigma capitado com papilas laterais. Fruto ca. $5 \times 5 \mathrm{~mm}$, arredondado, negro.

Material examinado: ALAGOAS: Olho d'Água do Casado, 4.VIII.2000, fr., R.A. Silva \& D. Moura 1599 (PEUFR). Piranhas, 4.V.1999, fl., D. Moura \& R.A. Silva 175 (PEUFR); 29.VII.1999, fl. e fr., D. Moura \& R.A. Silva 503 (PEUFR). SERGIPE: Canindé do São Francisco, 16.VIII.2000, fl., D. Moura \& R.A. Silva 1343 (PEUFR);2.VI.1999, fl., R.A. Silva \& D. Moura 425 (PEUFR); 5.V.2000, fl., J.I.M. Melo et al. 256(PEUFR); 8.VI.1999, fr., D. Moura \& M.F. Sales 354 (PEUFR); 3.VI.1999, fl., D. Moura 320 (PEUFR); 19.XI.1999, fr., R.A. Silva et al. 1288 (PEUFR); 24.XI.1999, fl., R.A. Silva \& D. Moura 1335 (PEUFR).

Esta é uma espécie amplamente distribuída nas regiões tropicais, comum na Índia e América do Sul, alcançando a Argentina, Bolívia, Brasil e Peru (Salimena 2000). No Brasil, está distribuída em todo o território, ocorrendo em vegetação litorânea, na Caatinga, no complexo Caatingacampo, no Cerrado, alcançando os domínios das florestas ombrófilas densas. Ocupa áreas de solos arenosos, argilosos e litólicos. É uma espécie muito frequente na área de estudo, sendo encontrada formando populações com muitos indivíduos em áreas abertas, de solos areno-argilosos e nas chapadas areníticas, florescendo e frutificando entre os meses de fevereiro e novembro. É facilmente reconhecida por apresentar inflorescências capituliformes, corola amarela a vermelha levemente encurvada e fruto arredondado negro. É uma espécie utilizada para fins ornamentais, devido à coloração exuberante de suas flores (Lorenzi \& Souza 2001), popularmente conhecida como chumbinho, cambará ou cambarazinho.
1.2. Lantana canescens Kunth. Nov. Gen. \& Sp. 2: 259. 1817.

Fig. 1g-k

Subarbusto ca. $35 \mathrm{~cm}$. Ramos cinéreos, subquadrangulares, glabros a escabros; internós 1,5-7,0 cm. Folhas cartáceas, levemente discolores; pecíolo cilíndrico, 5-7 mm compr., pubescente; limbo ovado, $0,9-4 \times 1-2,1 \mathrm{~cm}$, face superior pubescente, face inferior tomentosa, base atenuada, margem serreada, ápice acuminado. Inflorescências capituliformes, axilares (1 por axila), pedúnculo 1,5-7 cm compr., escabro a viloso; brácteas foliáceas, cartáceas, ovadas, 4 6,5 ×2-2,5 mm, pubescentes, ápice levemente caudado. Cálice denteado, ca. 0,9 ×0,9 mm, oblongo, pubescente, margem ciliada. Corola alva, ca. 6-8 mm compr., lobos ca. 2,5 × 1,5 $\mathrm{mm}$, fauce $1 \mathrm{~mm}$ diâm., tubo róseo, ca. $5 \mathrm{~mm}$ compr., externamente pubescente. Estames inseridos na metade do tubo, anteras elípticas. Ovário oblongo, ca. $0,5 \mathrm{~mm}$, glabro; estilete ca. 1,2 mm compr., estigma capitado com papilas laterais. Fruto não observado.

Material examinado: ALAGOAS: Piranhas, 10/VIII/ 1999, fl., D. Moura \& R.A. Silva 547 (PEUFR).

Material adicional examinado: BAHIA: Lagoa da Eugenia, 20.II.1974, fl., R.M. Harley et al. 16255 (IPA). PERNAMBUCO: Garanhuns, 20.IX.1981, fl., A. Ramires et al. (IPA 26371). Nazaré da Mata, 13.III.2002, fl., M.B. Costa e Silva et al. 2848 (IPA). Moreno, 30.XII.1933, fl., B. Pickel 3475 (IPA); 13.I.1934, fl., B. Pickel 3487 (IPA); 28.II.1934, fl., B. Pickel 3528 (IPA). Timabaúba, 25.III.2007, fl., J.G. Sena 74048 (IPA). PIAUÍ: Serra da Capivara, 1979, fl., L. Emperaire 624 (IPA). SERGIPE: Canindé do São Francisco, 9.VII.2005, fl., D. V. Braga et al. (IPA 73899).

O centro de distribuição de Lantana canescens encontra-se na América do Sul e México (Sanders 2001), estando amplamente distribuída em regiões tropicais do continente americano. No Brasil, distribui-se numa faixa desde o Pará até Minas Gerais, ocupando áreas de solos arenosos ou pedregosos, em Caatinga, florestas e lajeados úmidos, muitas vezes presente em substrato calcário. Em Xingó, $L$. canescens forma populações com poucos indivíduos, tendo sido encontrada apenas em Caatinga arbustiva, em solos litólicos. É facilmente reconhecida em campo por 

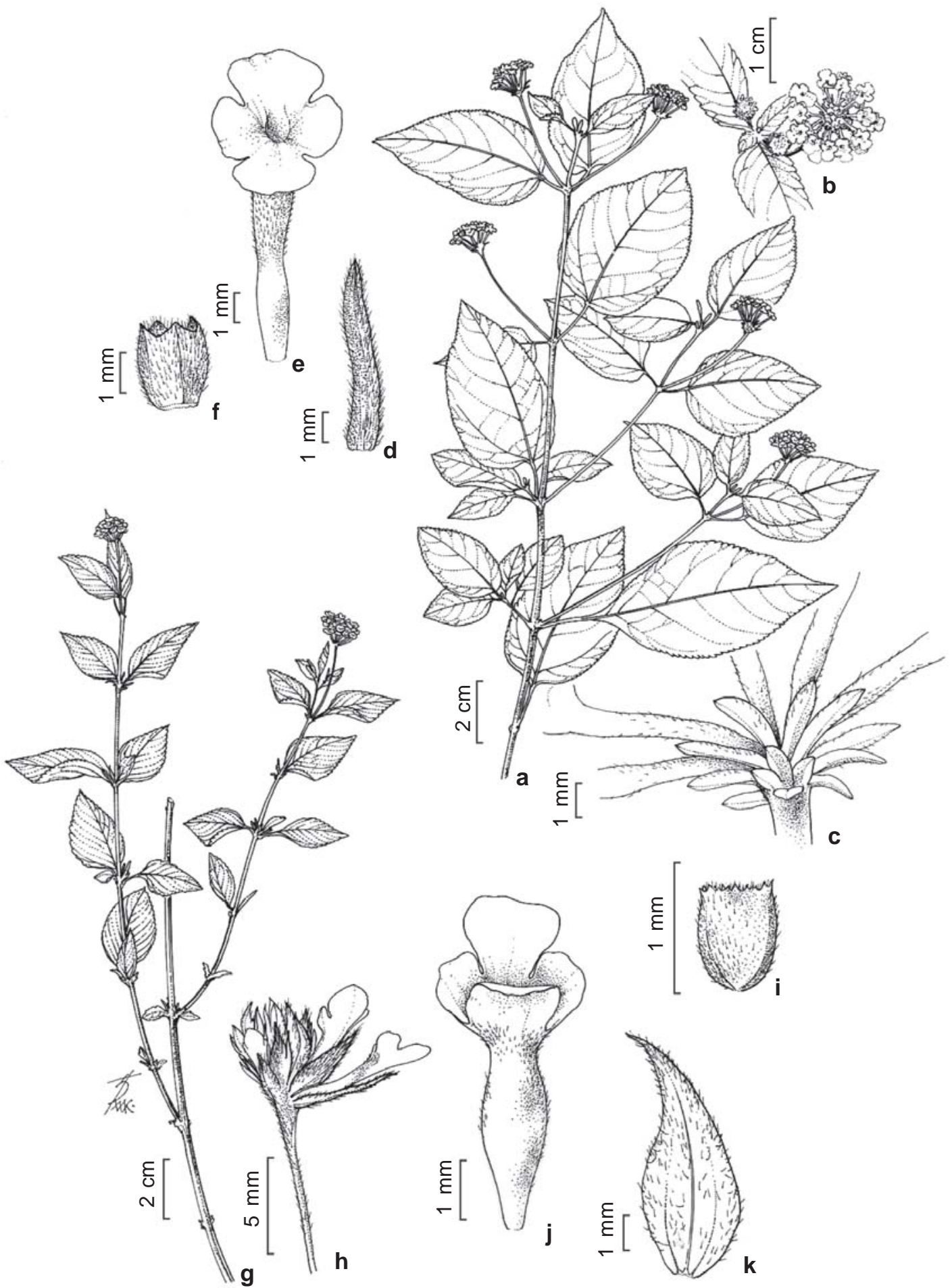

Figura 1 - a-f. Lantana camara L. - a. aspecto geral do ramo; b. inflorescência; c. base da inflorescência; d. bráctea; e. corola; f. cálice (Moura 21). g-k. Lantana canescens Kunth. - g. aspecto geral do ramo; h. inflorescência; i. cálice; j. corola; k. bráctea (Moura \& Silva 547).

Figure 1 - a-f. Lantana camara L. - a. habit; b. inflorescence; c. base of the inflorescence; d. bract; e. corolla; f. calyx (Moura 21). g-k. Lantana canescens Kunth. - g. habit; h. inflorescence; i. calyx; j. corolla; k. bract (Moura \& Silva 547). 
apresentar folhas ovadas, brácteas foliáceas e ovadas, com ápice levemente caudado, flores reunidas em inflorescências capituliformes e corola alva de tubo róseo. O material examinado indica floração durante todo o ano.

\section{Lippia L., Sp. P1. 1: 633. 1753.}

Subarbustos ou arbustos, raramente árvores. Ramos eretos, glabros, pubescentes, hirsutos ou tomentosos, tricomas simples ou glandulares. Folhas simples, decussadas ou verticiladas, raramente alternas, comumente decíduas, pecioladas ou sésseis, inteiras, denteadas ou lobadas, membranáceas a coriáceas. Inflorescências pedunculadas, solitárias ou fasciculadas, em corimbos, panículas, glomérulos ou espigas breves, axilares ou terminais; brácteas persistentes, ovais ou lanceoladas, decussadas, tetrásticas, plicadas. Flores andróginas ou unissexuadas por aborto, diminutas; cálice tubular, reduzido, ovado ou campanulado, membranáceo, 2-4 dentado; corola alva, rosa, magenta ou amarela, hipocrateriforme ou infundibuliforme, tubo cilíndrico, geralmente encurvado, ventricoso, lábio anterior 3-lobado, lábio posterior 2-lobado. Estames 4, didínamos, inclusos, inseridos no ventre; anteras ovadas ou elípticas, tecas paralelas ou divergentes, abortivas ou ausentes nas flores pistiladas de espécies dióicas. Ovário 2-carpelar, 1-carpelar por aborto; estilete reduzido, estigma oblíquo. Fruto esquizocárpico, separando-se na maturidade em 2 mericarpos.

$$
\text { Lippia é um gênero com }
$$
aproximadamente 254 representantes, entre espécies, subespécies e variedades, amplamente distribuídos nas América tropical e subtropical, sendo raros na porção tropical do Velho Mundo (Moldenke, 1973). Segundo Troncoso (1974), Brasil, Paraguai e Argentina são os países que apresentam a maior concentração de espécies do gênero. De acordo com Sanders (2001), o gênero é principalmente encontrado em regiões semiáridas da América do Sul e secundariamente na região noroeste dos Andes e planaltos mexicanos. A importância econômica do gênero está associada, principalmente, à constituição química das espécies, sendo bastante utilizadas na medicina como antiespasmódicas, estomáquicas, emenagogas, sedativas (Santana et al., 2008) e na indústria de perfumaria devido à presença de óleos essenciais. $\mathrm{Na}$ área de estudo está representada por quatro espécies.

\section{Chave para as espécies de Lippia ocorrentes na região de Xingó}

1. Folhas discolores, pecíolo cilíndrico; cálice pubescente ou velutino; corola alva ou creme .... 2 2. Brácteas ovais, velutinas; cálice pubescente; corola alva; anteras ovais .... 2.2. L. gracilis

2'. Brácteas lanceoladas, vilosas; cálice velutino; corola creme; anteras elípticas 2.3. L. microphylla

1'. Folhas concolores, pecíolo quadrangular; cálice viloso; corola lilás. 3

3. Limbo ovado; pedúnculo até $1 \mathrm{~cm}$; tubo da corola amarelo ... 2.1. L. alba

3'. Limbo lanceolado; pedúnculo maior que $3 \mathrm{~cm}$; tubo da corola alvo

2.4. L. pedunculosa

2.1 Lippia alba (Mill.) N. E. Br. ex Britton \& P.Wilson, Bot. Porto Rico 6: 141. 1925.

Fig. 2a-d

Subarbusto ca. 1 m. Ramos cinéreos, subquadrangulares, pubescentes; internós ca. 2,3 $\mathrm{cm}$. Folhas decussadas, cartáceas, concolores; pecíolo quadrangular, 3-5 mm compr., pubescente; limbo ovado, 1,6-1,9×0,9-1,3 cm, face superior vilosa, face inferior tomentosa, base aguda, margem serreada, ápice agudoacuminado, nervura inferior central proeminente. Glomérulos ou espigas curtas, axilares (1 por axila), ca. $4 \mathrm{~mm}$; pedúnculo ca. $4 \mathrm{~mm}$, pubescente; brácteas côncavas, orbiculares, ca. $4 \times 3 \mathrm{~mm}$, vilosas, ápice curtamente acuminado. Cálice infundibuliforme, bilobado; ca. $1,5 \times 1 \mathrm{~mm}$, viloso. Corola lilás, hipocrateriforme, ca. 5,5 mm, lobos 1-1,5×1 


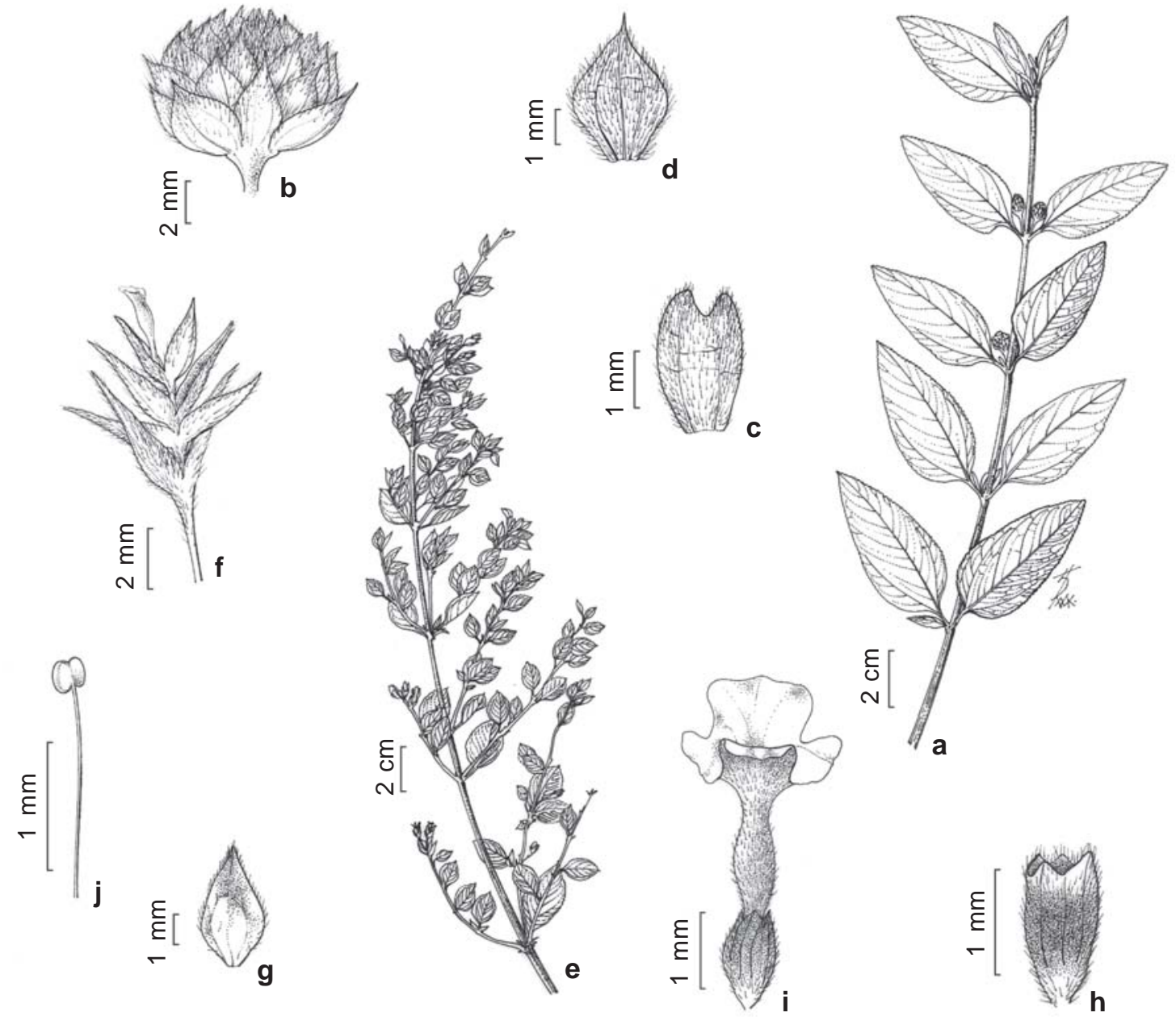

Figura 2 -a-d. Lippia alba (Mill.) N. E. Br. - a. aspecto geral do ramo; b. inflorescência; c. cálice; d. bráctea (Silva et al. 228). e-j. Lippia gracilis Schauer - e. aspecto geral do ramo; f. inflorescência; g. bráctea; h. cálice; i. flor; j. antera (Sales 762).

Figure 2 - a-d. Lippia alba (Mill.) N. E. Br. - a. habit; b. inflorescence; c. calyx; d. bract (Silva et al. 228). e-j. Lippia gracilis Schauer - e. habit; f. inflorescence; g. bract; h. calyx; i. flower; j. anther (Sales 762).

mm, fauce ca. 0,9 mm diâm., tubo amarelo, ca. $4 \mathrm{~mm}$ compr., externamente vilosa. Estames inseridos na porção média (os menores) e na metade superior (os maiores) do tubo; anteras elípticas, tecas divergentes. Ovário elíptico, ca. 0,7 mm compr., glabro; estilete ca. 1,3 mm compr., dilatado até a porção média inferior; estigma capitado, com papilas laterais. Fruto não observado.

Material examinado: ALAGOAS: Piranhas, 3.V.1999, fl., R. A. Silva et al. 228 (PEUFR).

Material adicional examinado: MARANHÃO: Timom, 19.XII.2000, fl., J.M. Maia \& W.R.R. Matos
54 (PEUFR). PERNAMBUCO: Caruaru, 12.VI.2000, fl. e fr., M.C. Cabral \& R.F. Oliveira 07 (PEUFR). Fazenda Nova, 14.IX.1998, fl., L.S. Figueirêdo \& W.M. Andrade 452 (PEUFR). Moreno, 25.IV.2005, fl., S. Brandão \& V. Santana (46777-PEUFR). Recife, Dois Irmãos, 20.VI.1990, fl., L.C. Gomes 85 (PEUFR). Ibura, 22.VIII.1991, fl., A. Krusch (11555PEUFR). Serra Talhada, VI.2001, fl., I.C.C. Cavalcanti s.n. (PEUFR 36799).

Segundo Sanders (2001), Lippia alba está amplamente difundida no Novo Mundo, ocorrendo desde as áreas subtropicais da América do Sul até o México, sendo extensivamente 
cultivada no Velho Mundo. No Brasil está amplamente distribuída nas Regiões Norte (AC, TO), Nordeste (AL, BA, CE, MA, PE), CentroOeste (DF, GO, MT), Sudeste (MG, RJ, SP) e Sul (PR, RS), habitando florestas de galeria, campos rupestres, Cerrado e Caatinga, em ambientes diversos, desde áreas úmidas a secas, em solos arenosos com cascalho e afloramentos de diabásio. Na região de Xingó L. alba é pouco frequente, ocorrendo principalmente em áreas perturbadas de solos areno-argilosos e pedregosos, em populações com poucos indivíduos. É facilmente reconhecida por apresentar folhas concolores, pecíolo quadrangular, pubescente, inflorescências em glomérulos ou espigas breves, cálice viloso e corola lilás com tubo amarelo. O material examinado evidencia que Lippia alba floresce entre os meses de maio e dezembro.

2.2 Lippia gracilis Schauer, Prodr. 11: 576. 1847. Fig. $2 \mathrm{e}-\mathrm{j}$

Arbusto 1-2,5 m, muito ramificado. Ramos cinéreos, subcilíndricos, glabros a pubescentes, internó ca. $5 \mathrm{~cm}$. Folhas decussadas, membranáceas, discolores; pecíolo cilíndrico, 2-8 mm compr., pubescente; limbo oval, 0,9$2,2 \times 0,4-1,3 \mathrm{~cm}$, face superior escabra, face inferior pubescente a tomentosa, base acumeada a obtusa, margem crenada, ápice agudo, nervuras proeminentes com maior quantidade de tricomas. Espigas curtas, axilares ( 3 por axila), ca. $4 \mathrm{~mm}$; pedúnculo 4-6 cm compr., pubescente; brácteas côncavas, ovais, ca. $4,5 \mathrm{~mm}$, velutinas, carenadas, com ápice acuminado, dispostas em 4 séries, decussadas. Cálice tubular, 4-dentado; ca. 1,5× $1 \mathrm{~mm}$, pubescente. Corola alva, hipocrateriforme, ca. $5 \mathrm{~mm}$ compr., lobos ca. $1,5 \times 1 \mathrm{~mm}$, fauce ca. 0,4 mm diâm., tubo ca. $3 \mathrm{~mm}$ compr, externamente pubescente. Estames inseridos na metade superior do tubo; anteras ovais, tecas paralelas. Ovário orbicular, ca. $0,5 \mathrm{~mm}$ compr., glabro; estilete ca. $2 \mathrm{~mm}$ compr.; estigma capitado, com papilas laterais. Fruto não observado.

Material examinado: ALAGOAS: Piranhas, 4.IV.2001, fl., L.M. Cordeiro et al. 350 (PEUFR). SERGIPE: Canindé do São Francisco, 9.VI.1999, fl., R.A. Silva \& M.F. Sales 513 (PEUFR); 7.VI.1999, fl., R.A. Silva \& M.F. Sales 465 (PEUFR); 8.VI.1999, f1., M.F. Sales 762 (PEUFR).
Material adicional examinado: BAHIA: Sento-Sé, 4.I.1990, fl., A.M. Miranda \& F. Esteves 55 (PEUFR). PERNAMBUCO: Buíque, 4.IX.1995, fl., M.F. Lucena \& L.S. Figueiredo 44 (PEUFR). Floresta, 27.IV.1989, fl., M.J.N. Rodal 36 (PEUFR). Serra Talhada, 5.II.1998, fl., A. Sacramento et al. 250 (PEUFR); 1.V.2000, fl., I.C.C. Cavalcanti s.n. (PEUFR 31391).

Lippia gracilis ocorre no Brasil nas Regiões Norte (PA), Nordeste (MA, PI, CE, RN, PB, PE, AL, SE, BA), Centro-Oeste (GO) e Sudeste (MG e ES), ocorrendo em matas de encosta, Caatinga e Cerrado, em solos arenosos, campose afloramentos rochosos. Na área estudada, a espécie é pouco encontrada, com populações de poucos indivíduos ocorrendo em pontos isolados de campos pedregosos. Assemelha-se a L. microphylla por apresentarem espigas curtas e brácteas côncavas, dispostas em quatro séries. No entanto, diferenciam-se por L. gracilis apresentar brácteas decussadas, ovais, velutinas, com carena bastante evidente, cálice pubescente, corola alva e anteras ovais. Apresenta importância farmacológica devido à atividade antimicrobiana contra muitas espécies de fungos e bactérias (Albuquerque et al. 2006). O material examinado evidencia floração e frutificação entre os meses de janeiro e junho.

2.3 Lippia microphylla Cham. Linnaea 7: 226. 1832.

Fig. 3a-f

Arbusto ca. 1,5 m, muito ramificado. Ramos castanhos, subquadrangulares, pubescentes; internó 2-3 cm compr. Folhas decussadas, cartáceas, fortemente discolores; pecíolo cilíndrico, 4-8 mm compr., pubescente; limbo ovado, $1-2 \times 0,5-1,5 \mathrm{~cm}$, face superior escabra a pubescente, face inferior tomentosa, superfície bulada, base aguda, margem crenada, ápice agudo. Espigas curtas, axilares (2-4 por axila), ca. $7 \mathrm{~mm}$; pedúnculo ca. $5 \mathrm{~mm}$ compr., viloso; brácteas côncavas, lanceoladas, ca. $5 \mathrm{~mm}$ compr., vilosas, ápice longamente acuminado, dispostas em arranjo imbricado. Cálice ovado, 4-dentado; ca. $2 \times 1 \mathrm{~mm}$, velutino. Corola creme, hipocrateriforme, ca. $6 \mathrm{~mm}$ compr., lobos ca. $1,5 \times 2 \mathrm{~mm}$, fauce ca. $0,9 \mathrm{~mm}$ diâm., tubo ca. 4,5 mm compr., externamente pubescente. Estames inseridos na metade superior do tubo; anteras elípticas, tecas paralelas. Ovário oblongo, ca. $0,9 \mathrm{~mm}$ compr., glabro; estilete ca. $2 \mathrm{~mm}$ 


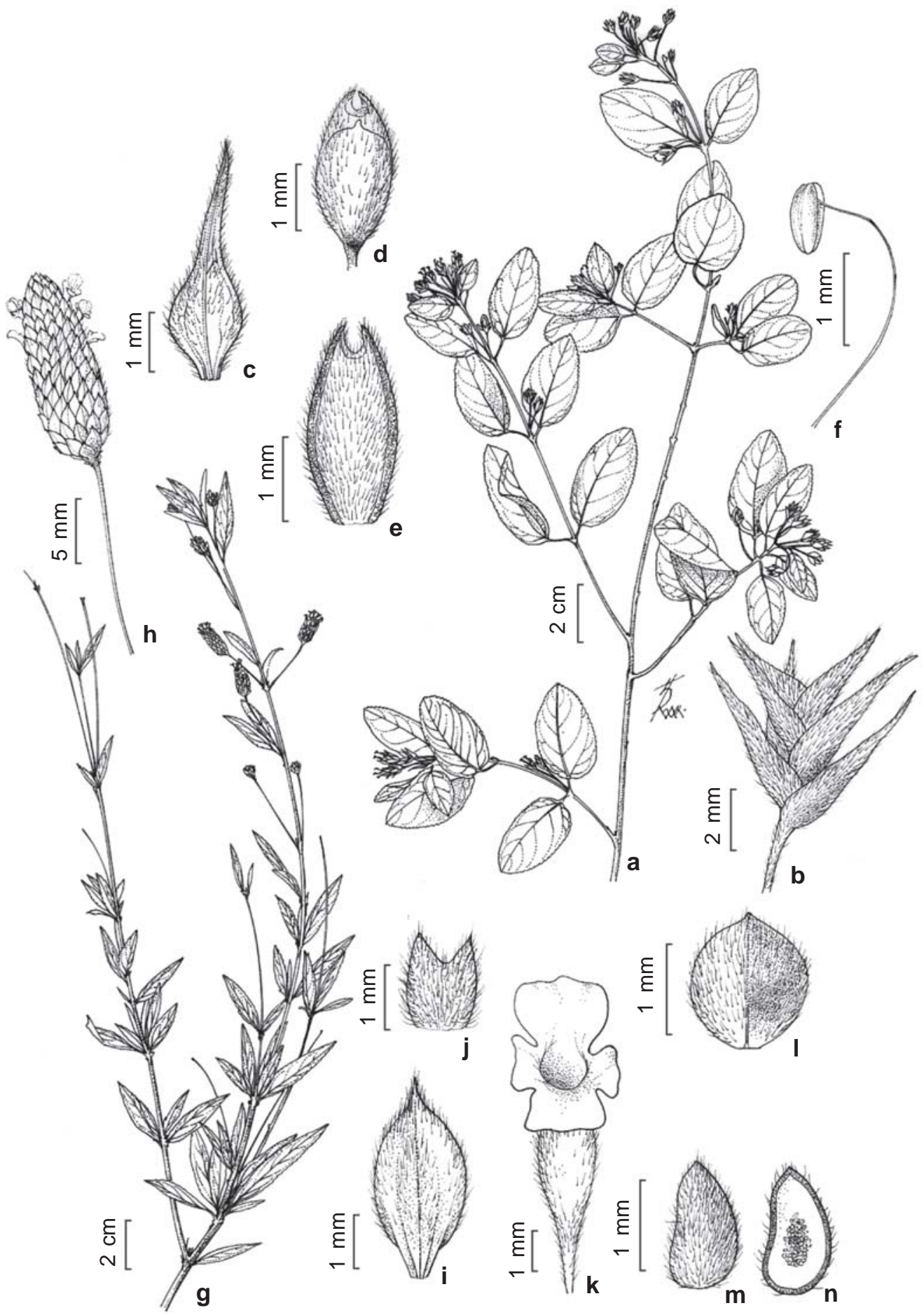

Figura 3 - a-f. Lippia microphylla Cham. - a. aspecto geral do ramo; b. inflorescência; c. bráctea; d. fruto; e. cálice; f. antera (Moura \& Silva 632). g-n. Lippia pedunculosa Hayek - g. aspecto geral do ramo; h. inflorescência; i. bráctea; j. cálice; k. corola; 1. aspecto geral do fruto; m. parte externa do fruto; n. parte interna do fruto (Moura 49).

Figure 3 - a-f. Lippia microphylla Cham. - a. habit; b. inflorescence; c. bract; d. fruit; e. calyx; f. anther (Moura \& Silva 632). g-n. Lippia pedunculosa Hayek - g. habit; h. inflorescence; i. bract; j. calyx; k. corolla; 1. fruit; m. fruit, outside view; n. fruit, inside view (Moura 49). 
compr., estigma capitado, com papilas laterais. Fruto ovado, ca. $2 \times 1 \mathrm{~mm}$ compr.

Material examinado: SERGIPE: Canindé do São Francisco, 24.VIII.1999, fl., D. Moura \& R.A. Silva 632 (PEUFR).

Material adicional examinado: BAHIA: Campo Formoso, 16.IV.1973, fl., D.P. Lima 13127 (PEUFR). Ilhéus, 24.X.1972, fl., D.P. Lima 13102 (PEUFR). PERNAMBUCO: Buíque, 5.V.1995, fl., A. Laurênio et al. 30 (PEUFR); 21.IX.1995, fl., K. Andrade et al. 215 (PEUFR). Floresta, 20.IV.1989, fl., M.J.N. Rodal 37 (PEUFR). Petrolina, 24.III.1966, fl. e fr., J.S. Sobrinho 229 (PEUFR).

Lippia microphylla distribui-se desde as Guianas até o Rio Grande do Sul, sendo encontrada em matas de tabuleiro, florestas abertas, Caatinga, complexo Caatinga-campo e Cerrado, associada a solos pedregosos ou arenosos violáceos com afloramentos rochosos e crescendo entre rochas areníticas e graníticas. Os exemplares examinados evidenciam que a espécie é simpátrica com $L$. gracilis, apresentando uma maior faixa de ocorrência, estendendo-se de Roraima até o Rio Grande do Sul. Em Xingó, é pouco frequente, formando populações com até dez indivíduos. É facilmente reconhecida por apresentar folhas discolores, brácteas não carenadas, dispostas em 4 séries com arranjo imbricado, lanceoladas, vilosas, cálice velutino, corola creme e anteras elípticas. Floresce entre os meses de março e setembro.

2.4. Lippia pedunculosa Hayek, Repert. Spec. Nov. Regni Veg. 2:87. $1906 . \quad$ Fig. 3g-n

Subarbusto ou arbusto 0,7-1,5 m. Ramos cinéreos, subquadrangulares a quadrangulares, glabros, interno $2,5-7 \mathrm{~cm}$. Folhas decussadas, cartáceas, concolores; pecíolo cilíndrico, 2-4 mm compr., pubescente; limbo lanceolado, 2,1-4,9× 0,6-1,6 cm, face superior pubescente, face inferior tomentosa, base atenuada, margem dentada, ápice agudo. Espigas longas axilares ( 1 por axila), 0,71,8 cm; pedúnculo 3,1-7,3 cm compr., pubescente; brácteas côncavas, ovais, 3,5-4 mm, vilosas, ápice acuminado. Flores subsésseis, pedicelo discóide. Cálice ovado, 2-dentado; 1,5×1 mm, viloso. Corola lilás, infundibuliforme, ca. $6,0 \mathrm{~mm}$ compr., lobos 1,5-2 mm, fauce ca. $1 \mathrm{~mm}$ diâm., tubo $4 \mathrm{~mm}$ compr., constrito na base, externamente velutina. Estames inseridos na metade inferior do tubo; anteras ovadas, tecas paralelas. Ovário ovado, ca. 0,5 mm compr.; estigma capitado, com papilas laterais. Fruto ovado, $1 \times 1 \mathrm{~mm}$ compr. Material examinado: ALAGOAS: Piranhas, 25.VIII.1999, fl. efr., R.A. Silva \& D. Moura 964 (PEUFR). SERGIPE: Canindé do São Francisco, 14.IV.1999, fl. e fr., $D$. Moura 49 (PEUFR); 24.VIII.1999, fl. e fr., D. Moura 640 (PEUFR); 6.IX.1999, fl. e fr., R.A. Silva \& D. Moura 998 (PEUFR).

No Brasil, Lippia pedunculosa é encontrada apenas nas Regiões Nordeste (AL, SE) e Sudeste (SP). Na Região Nordeste ocorre em áreas de Caatinga, com vegetação rala e substrato pedregoso. Na área de estudo é rara, ocorrendo em solo argiloso, em geral com capeamento pedregoso.É facilmente reconhecida por suas folhas concolores, limbo laceolado, pecíolo pubescente, inflorescências com pedúnculo maior que $3 \mathrm{~cm}$, cálice viloso e corola lilás de tubo alvo. Distingue-se das demais por apresentar longas e solitárias inflorescências espiciformes com até $1,8 \mathrm{~cm}$ compr., associadas a pedúnculos de até $7,3 \mathrm{~cm}$ compr. Floresce e frutifica entre os meses de abril e setembro.

3. Stachytarpheta Vahl, Enum. Pl. 1:205. 1804. nom. cons.

Ervas ou subarbustos. Ramos comumente subcilíndricos, indumento simples ou pluricelular. Folhas simples, decussadas, verticiladas ou alternas, denteadas ou crenadas. Inflorescências sésseis, terminais, espigas longas ou curtas, multifloras ou ocasionalmente paucifloras; brácteas estreitas, raramente largas, ovais ou lanceoladas, imbricadas, persistentes, 1 por flor. Flores andróginas; cálice longo, estreito, tubular, membranáceo ou cartáceo, 4-5 dentado ou 4-5 lobado, por vezes vezes bipartido; corola laranja, vermelha, alva, azul, lilás, púrpura até negra, hipocrateriforme, tubo cilíndrico, reto ou encurvado, 5-lobada, lobos amplos, obtusos, iguais ou ligeiramente desiguais. Estames 2, estaminódios 2, filiformes, inclusos; anteras oblongas ou ovadas, tecas divergentes. Ovário 2-carpelar, oblongo; estilete longamente filiforme, estigma capitado ou orbicular. Fruto esquizocárpico, separando- 
se na maturidade em 2 mericarpos ósseos. Sementes lineares.

O gênero Stachytarpheta possui aproximadamente 133 espécies, sendo o Brasil o centro de sua diversidade com 79 espécies, incluindo táxons infra-específicos; é um gênero quase que exclusivo do novo mundo, com apenas uma espécie ocorrendo no Velho Mundo (Atkins 2005), frequentemente encontrado em ambientes úmidos e sombreados.

\section{Chave para as espécies de Stachytarpheta ocorrentes na região de Xingó}

1. Ramos quadrangulares a subcilíndricos, glabros; raque verde-arroxeada; corola lilás a roxa; anteras oblongas 3.1. S. angustifolia

1'. Ramos cilíndricos, pubescentes; raque verde; corola vermelho-sangue; anteras ovadas 3.2. S. microphylla

3.1 Stachytarpheta angustifolia (Mill.) Vahl., Enum. Pl. 1: 205-206. 1804. Fig. $4 \mathrm{a}-\mathrm{f}$

Ervaca. $30 \mathrm{~cm}$. Ramos verdes, quadrangulares a subcilíndricos, glabros; internós 2,5-4,5 cm. Folhas decussadas, cartáceas; pecíolo quadrangular, ca. $8 \mathrm{~mm}$ compr., pubescente; limbo ovado, 3,5-9,9 $\times 0,5-1,9 \mathrm{~cm}$, glabro, base aguda, margem serreada, ápice agudo, nervuras proeminentes, pubescente, com tricomas unicelulares. Espiga multiflora; raque suculenta, verde-arroxeada, glabra; brácteas ovadas, 3,5-7,5 mm compr., glabras, margem ciliada. Cálice ca. $7 \times 1,5 \mathrm{~mm}$; membranáceo, escabro. Corola lilás a roxa, infundibuliforme, $0,8-1,2 \mathrm{~cm}$ compr, lobos ca. $5 \times 5 \mathrm{~mm}$, fauce ca. $1 \mathrm{~mm}$ diâm., tubo ca. $6 \mathrm{~mm}$ compr., glabra. Estames inseridos na metade inferior do tubo da corola, filetes com tricomas glandulares; anteras oblongas, ca. 0,9 mm compr. Ovário oblongo, 1-2 mm compr., glabro; estilete ca. $6 \mathrm{~mm}$ compr., glabro, estigma capitado. Fruto oblongo, negro, ca. $3 \mathrm{~mm}$ compr. Material examinado: ALAGOAS: Piranhas, 4.V.1999, fl., D. Moura 174 (PEUFR); 16.VIII.1999, fl., R.A. Silva \& Moura 848 (PEUFR).

Material adicional examinado: PERNAMBUCO: Caruaru, 5.IX.1995, fr., A.B. Marcon et al. 63 (PEUFR). Itamaracá, 30.VII.1992, fl. e fr., A.M. Miranda 540 (PEUFR). Paulista, XI.1992, fl., L.C. Gomes 289 (PEUFR). Recife, 2.VIII.1958, fl. e fr., A. Lima \& $S$. Leitão (1379-PEUFR); 16.X.1960, fl. e fr., A.M. Miranda (78-PEUFR). RIO GRANDE DO NORTE: Tibau do Sul, 6.VIII.1999, fr., R. Figueirôa 29 (PEUFR).

Stachytarpheta angustifolia é encontrada principalmente em lugares úmidos e pantanosos, com larga distribuição na América Tropical, frequentemente na América do Sul. No Brasil, distribui-se nos estados do Amapá, Mato Grosso, Ceará, Paraíba, Pernambuco, Bahia e Minas Gerais, ocorrendo em restinga arbustiva, brejos e Caatinga, sobre solos ricos em matéria orgânica, arenosos e pedregosos (Atkins 2005). Na área estudada é frequente em lugares úmidos ou alagados, apresentando populações com muitos indivíduos. Pode ser reconhecida por apresentar ramos quadrangulares a subcilíndricos, glabros, raque verde-arroxeada e suculenta, corola lilás a roxa e anteras oblongas. O material analisado mostrou que $S$. angustifolia floresce e frutifica entre os meses de maio e outubro, coincidindo com o período chuvoso na região.

\subsection{Stachytarpheta microphylla Walp., Enum. Pl. 1: 205. $1804 . \quad$ Fig. 4g-j}

Subarbusto ca. $50 \mathrm{~cm}$. Ramos castanhos, cilíndricos, pubescentes; internó 1,2-2,4 cm, a $5 \mathrm{~mm}$ da axila foliar. Folhas decussadas, cartáceas; pecíolo quadrangular, ca. $3 \mathrm{~mm}$ compr., pubescente; limbo, oval, $1-4,7 \times 0,5-1,8 \mathrm{~cm}$, escabro, nervuras proeminentes e pubescentes com tricomas pluricelulares, base curtamente atenuada, margem serreada, ápice agudo. Espiga multiflora; raque delgada, verde, pubescente; brácteas oblongas, ca. $9 \times 2,5 \mathrm{~mm}$, puberulentas, margem ciliada, ápice acuminado. Cálice bipartido, ca. $1 \times 0,2 \mathrm{~cm}$; membranáceo, escabro. Corola vermelho-sangue, hipocrateriforme, ca. 1,8 cm compr., 5-lobada, lobos 3-4 ×2-3 mm, fauce ca. $3 \mathrm{~mm}$ diâm., tubo 1,3-1,4 cm compr., glabra. Estames inseridos na metade do tubo da corola; filetes glabros, anteras ovadas, ca. $2 \mathrm{~mm}$ compr. Ovário oblongo, 1-1,5 mm compr., glabro; 


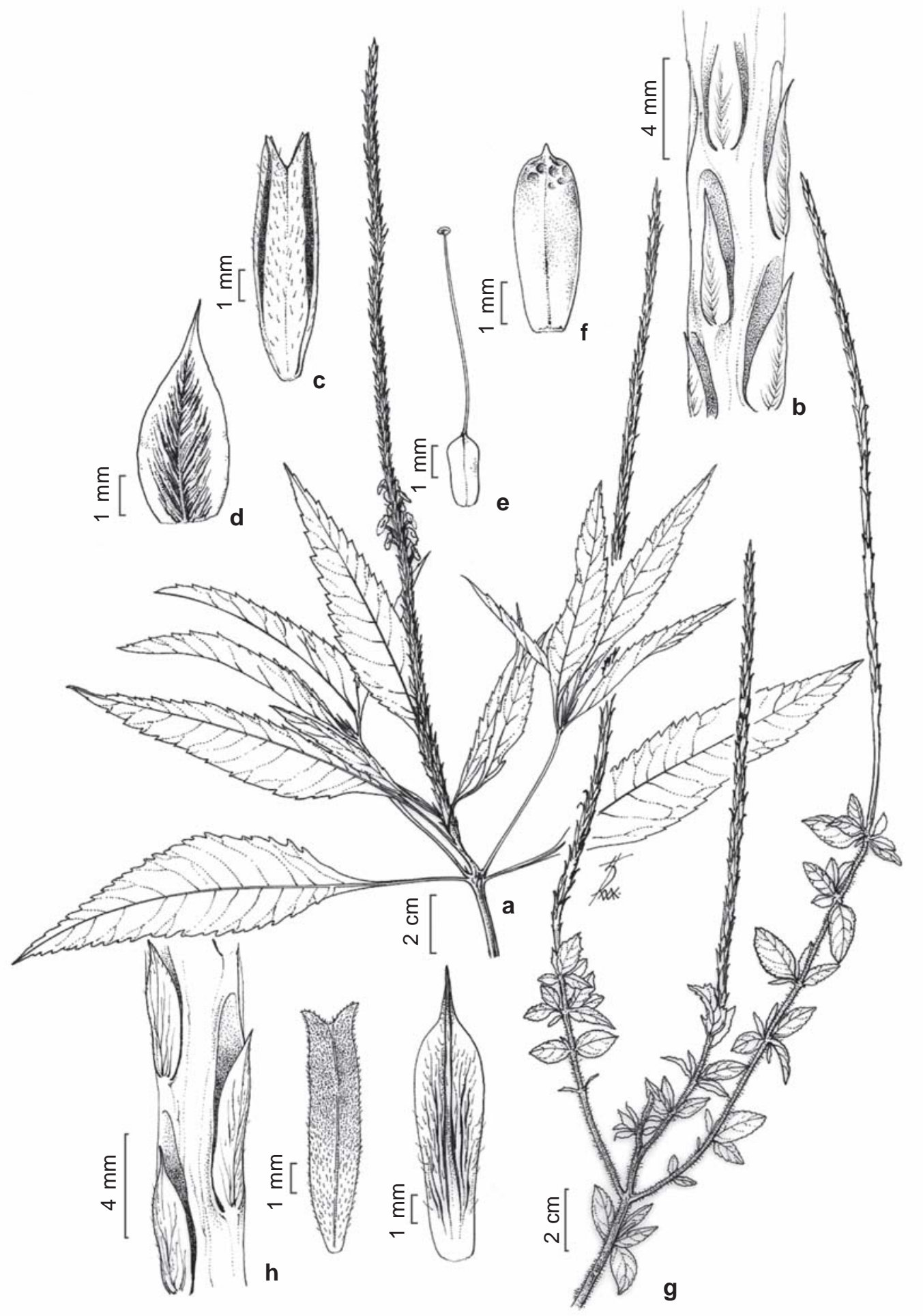

Figura 4 - a-f. Stachytarpheta angustifolia (Mill.) Vahl. - a. aspecto geral do ramo; b. inflorescência; c. cálice; d. bráctea; e. gineceu; f. fruto (Moura 174). g-j. Stachytarpheta microphylla Walp. - g. aspecto geral do ramo; h. inflorescência; i. cálice; j. bráctea (Moura \& Silva 1294).

Figures 4 - a-f. Stachytarpheta angustifolia (Mill.) Vahl. - a. habit; b. inflorescence; c. calyx; d. bract; e. gynoecium; f. fruit (Moura 174). g-j. Stachytarpheta microphylla Walp. - g. habit; h. inflorescence; i. calyx; j. bract (Moura \& Silva 1294). 
estilete ca. $8 \mathrm{~mm}$, glabro, estigma capitado. Fruto não observado.

Material examinado: ALAGOAS: Olho D'Água do Casado, 20.VII.2000, fl., D. Moura \& R.A. Silva 1294 (PEUFR). SERGIPE: Canindé do São Francisco, 24.VIII.1999, fl., D. Moura \& R.A. Silva 632 (PEUFR).

Stachytarpheta microphylla possui distribuição tropical, estando presente no Brasil nos estados de Pernambuco, Alagoas, Sergipe e Bahia. De acordo com Atkins (2005), embora possua uma estreita faixa de distribuição, é uma espécie razoavelmente comum e pouco exigente, podendo rapidamente colonizar terrenos adversos, com vegetação perturbada, a beira de estradas, solos pedregosos e áreas de Caatinga densa. Em Xingó, é pouco frequente, sendo encontrada formando populações com poucos indivíduos em solos arenosos. Distingue-se de $S$. angustifolia por possuir hábito subarbustivo, ramos cilíndricos, pubescentes, raque verde e delgada, corola vermelho-sanguíneo e anteras ovadas. Em Xingó, foi observada em floração entre os meses de julho e agosto.

\section{Agradecimentos}

A Franck Silva, pelo auxílio nas ilustrações.

\section{REFERÊNCIAS BIBLIOGRÁFICAS}

Abu-Asab, M.S. \& Cantino, P.D. 1992. Pollen morphology in subfamily Laminoideae phylogenetics implicatons. In: Harley, R. M. \& Reynolds, T. (eds.). Advances in Labiate science. Royal Botanic Gardens, Kew. 97-112.

Albuquerque, C.C.; Camara, T.R.; Mariano, R.L. R.; Willadino, L.; Marcelino Jr., C. \& Ulisses, C. 2006. Antimicrobial action of the essential oil of Lippia gracilis Schauer. Brazilian Archives of Biology and Technology 4(49): 527-535.

APG II. 2003. An update of the Angiosperm Phylogeny Group classification for the orders and families of flowering plants: APG II. Botanical Journal of the Linnean Society 141:399-436.

Atkins, S. 2005a. Verbenaceae. In: Kubitzki (ed.). The families and genera of flowering plants, Lamiales. Vol. 7. Springer, Berlin. Pp. 449-462.

Atkins, S. 2005b. The genus Stachytarpheta (Verbenaceae) in Brazil. Kew Bulletin 60: 161-272.
Bentham, G. 1876. Verbenaceae. In: Bentham, G. \& Hooker, J.D. (eds.). Genera plantarum. Vol.2. London. Pp. 1132-1136.

Briquet, I. 1897. Verbenaceae. In: Engler, A. \& Prantl, K. (eds.). Die natürlich Pflanzenfamilien 4(3A): 132-182.

Brummitt, R.F. \& Powell, C.E. 1992. Authors of plants names. Royal Botanic Gardens, Kew. 732p.

Cantino, P.D. 1992a. Evidence for a polyphyletic origin of the Labiatae. Annals of the Missouri Botanical Garden 79: 361-379.

Cantino, P.D. 1992b. Toward a phylogenetic classification of the Labiatae. In: Harley, R.M. \& Reynolds, T. (eds). Advances in Labiate science. Royal Botanic Gardens, Kew. Pp. 27-37.

Cantino, P.D.; Harley, R.M. \& Wagstaff, S.J. 1992. Genera of Labiatae: status and classification. In: Harley, R.M. \& Reynolds, T. (eds). Advances in Labiate Science. Royal Botanic Gardens, Kew.Pp. 511-522.

Cavalcanti, M.A.Q.; Oliveira, L.G.; Fernandes, M.J. \& Lima, D.M. 2006. Fungos filamentosos isolados do solo em municípios da região Xingó, Brasil. Acta Botanica Brasilica 20(4): 831-837.

Dua, V.K.; Pandey, A.C.; Singh, R.; Sharma, V.P. \& Subbarao, S.K. 2003. Isolation of repellent ingredient from Lantana camara (Verbenaceae) flowers and their repellency against Aedes mosquitoes. Journal of Applied Entomology 127: 509-511.

El-Gazzar, A. \& Watson, L. 1970. A taxonomic study of Labiatae and related genera. New Phytologia 69: 451-486.

Harley, R.M. \& Simmons, N.A.1986. Florula of Mucugê, Chapada Diamantina, Bahia, Brasil. Royal Botanical Gardens, Kew. Pp. 204-207.

Harris, J.G. \& Harris, M.W. 2001. Plant identification terminology: an illustrated glossary. Spring Lake Pub., Spring Lake. 216p.

INPE. Instituto Nacional de Pesquisas Espaciais. 2001. Boletim Metereológico 3: 25.

Holmgren, P.K.; Holmgren, N.H. \& Barnett, L.C. 1990. Index Herbariorum. Part 1. The herbaria of the world. 8 ed. New York Botanical Garden, New York. 693p.

Jansen-Jacobs, M.J. 1988. Verbenaceae. In: Görtzvan Rijn, A.R.A. (ed.). Flora of the Guianas. Koeltz, Germany. 4(18): 3-86.

Judd, W.S.; Campbell, C.S.; Kellogg, E.A.; Stevens, P.F. \& Donoghue, M.J. 2009. Sistemática vegetal: um enfoque filogenético. 3nd. Artmed. 632p. 
Junell, S. 1934. Zur Gynäceummorphologie und Systematik der Verbenaceen und Labiaten. Symbolae Botanicae Upsalienses 4: 1-219.

Lorenzi, H. \& Souza, H.S. 2001. Plantas ornamentais do Brasil: arbustivas, herbáceas e trepadeiras. Instituto Plantarum de Estudos da Flora, Nova Odessa. Pp. 1030-1056.

Luizi-Ponzo, A.P. 1997. Verbenaceae. In: Marques, M.C.M.; Vaz, A.S.F. \& Marquete, R. (eds.). Flórula da APA Cairuçu, Parati, Rio de Janeiro. Instituto de Pesquisas Jardim Botânico do Rio de Janeiro. Série Estudos e Contribuições 14: 558-564.

Macbride, J.F. 1960. Verbenaceae. In: Macbride, J.F. (ed.). Flora of Peru. Field Museum of Natural History. 13(5A): 609-720.

Moldenke, H.N. 1973. Verbenaceae. In: Woodson Jr., R.E. \& Schery, R.W. (eds.). Flora of Panamá. Annals of the Missouri Botanical Garden 60: 41-148.

Moreira, R.C.R.; Lopes, T.C.; Bezerra, J.L.; Guerra, R.N.M.; Rêbelo, J.M.M.; Ribeiro, M.N.S.; Nascimento, F.R.F. \& Costas, J.M.L. 2007. Efeito leishmanicida in vitro de Stachytarpheta cayennensis (Rich) Vahl (Verbenaceae). Revista Brasileira de Farmacognosia 17 (1): 59-63.

Múlgra de Romero, M.E.; Rotman, A.D. \& Atkins, S. 2003. Verbenaceae. Flora fanerogâmica argentina. Proflora, Argentina, 84 (253).

Raj, B. 1983. A contribution to the pollen morphology of Verbenaceae. Review of Paleobotany and Palynology. 39: 343-422.

Salimena, F.R.G. 2000. Verbenaceae. In: Melo, M.M.R.F.; Barros, F.; Wanderley, M.G.L.; Kirizawa, M.; Jung-Mendaçolli, S.L. \& Chiea, S.A.C. (eds.). Flora fanerogâmica da Ilha do Cardoso, São Paulo. Instituto de Botânica, São Paulo 7: 7-26.

Salimena-Pires, F.R. \& Giulietti, A.M. 1998. Verbenaceae da Serra do Cipó, Minas Gerais: Verbenaceae. Boletim de Botânica da Universidade de São Paulo 17: 155-186.

Sanders, R.W. 2001. The genera of Verbenaceae in the southeastern United States. Harvard Papers in Botany 5(2): 303-358.

Santana, D.L.; Preza, D.L.C.; Assis, J.G.A.; Guedes, M.L.S. 2008. Plantas com propriedades terapêuticas utilizadas na comunidade de campos, Amélia Rodrigues, Bahia. Magistra, Cruz das Almas-BA 20(3): 218-230.
Schauer, J.C. 1847. Verbenaceae. In: De Candolle, A.P. (ed.). Prodromus Systematis Naturalis Regni Vegetabilis. Paris \& Leipzig 11: 522-700.

Schauer, J.C. 1851 Verbenaceae. In: von Martius, C.F.P. \& Eichler, A.G. (eds). Flora brasiliensis. Typographia Regia, Munchen, Wien, Leipzig 9: 166-307.

Shoun-Liang, C. \& Gilbert, M.G. 1994. Verbenaceae through Solanaceae. In: Wu ZhengYi, Raven, P.H. (eds.). Flora da China. Science Press 17: 1-49.

Silva, T.R.S. 1999. Redelimitação e revisão taxonômica do gênero Lantana L. (Verbenaceae) no Brasil. Tese de Doutorado. Universidade de São Paulo, São Paulo. 176p.

Souza, V.C. \& Lorenzi, H. 2005. Verbenaceae. Botânica sistemática. Instituto Plantarum de Estudos da Flora, Nova Odessa. Pp. 529-532.

Stanndard, B.L. 1995. Flora of the Pico das Almas, Diamantina, Bahia, Brasil. Royal Botanic Gardens, Kew. 853p.

Steane, D.A.; de Kok, R.P.J. \&. Olmstead, R.G. 2004. Phylogenetic relationships between Clerodendrum (Lamiaceae) and other Ajugoid genera inferred from nuclear and chloroplast DNA sequence data. Molecular Phylogenetics and Evolution 32: 39-45.

Stefanini, M.B.; Rodrigues, S.D.; Ming, L.C. 2002. Ação de fitorreguladores no crescimento de erva-cidreira-brasileira. Horticultura Brasileira 20(1): 18-23.

Troncoso, N.S. 1974. Los gêneros de Verbenáceas de Sudamérica extratropical (Argentina, Chile, Bolívia, Paraguay, Uruguay y sur de Brasil). Darwiniana 18: 295-407.

Veloso, H.P.; Rangel Filho, A.L.R. \& Lima, J.C.A. 1992. Classificação da vegetação brasileira: adaptada a um sistema universal. Instituto Brasileiro de Geografia e Estatística, Rio de Janeiro. 124p.

Wagstaff, S.F. 1992. A phylogenetic interpretation of pollen morphology in tribe Mentheae (Labiatae). In: Harley, R.M. \& Reynolds, T. (eds.). Advances in Labiate science. Royal Botanic Gardens, Kew. Pp. 113-124.

Wagstaff, S.J.; Hickerson, L.; Sprangler, R.; Reeves, P.A. \& Olmestead, R.G. 1998. Phylogeny in Labiatae s. 1., inferred from cpDNA sequences. Plant Systematics and Evolution. 209: 265-274. 